\title{
Artesanía qom: ¿estrategia de subsistencia en la ciudad o lazo de unión y expresión de lo colectivo comunitario?
}

\section{Nadia Voscoboinik, ${ }^{1}$ Griselda Laura Aragon ${ }^{2}$ y Hugo Car- dozo 3}

1 Laboratorio de Investigaciones en Antropología Social (LIAS), Facultad de Ciencias Naturales y Museo (FCNyM), Universidad Nacional de La Plata (UNLP), La Plata, Argentina.

Correo electrónico: nadia_v92@hotmail.com

2 Laboratorio de Investigaciones en Antropología Social (LIAS), Facultad de Ciencias Naturales y Museo (FCNyM), Universidad Nacional de La Plata (UNLP), La Plata, Argentina.

Correo electrónico: glauraaragon@gmail.com

3 Comunidad Dalaxaic' Na'ac

Correo electrónico: hugocardozo77@gmail.com
Recibido:

4 de mayo de 2020 Aceptado:

9 de febrero de 2021

doi: 10.34096/runa.v42i2.7664

\section{Resumen}

Este trabajo presenta diversas narrativas de un referente y líder de una comunidad qom de La Plata que dan cuenta de su experiencia migratoria, de la producción artesanal en la ciudad y de las lógicas colectivo comunitarias que las sustentan. Metodológicamente utilizamos lo que se ha denominado como "producción de conocimiento conjunto", definido como un diálogo con el campo -en el que entendemos a los referentes qom como interlocutores- y un diálogo con la academia -en el que se rescatan aquellas conceptualizaciones que contribuyen a interpretar la situación objeto de estudio y superar la clásica relación investigador/investigado-. La coautoría de este trabajo con el líder y artesano qom de la comunidad se enmarca y es continuidad de otras experiencias de producción de conocimiento conjunto, guiadas por la problematización de las nociones teóricas de identidad étnica/etnicidad/clase social/ experiencia/ lógicas colectivo- comunitarias, que permiten profundizar en el conocimiento de la práctica artesanal del pueblo qom.

\section{Palabras clave}

Qom; Artesanías; Lógicas colectivo-comunitarias; Identidad étnica; Migración 


\title{
Qom handicraft: livelyhood strategy in the city or bond of union and expresion of the collective community?
}

\begin{abstract}
Key words

Qom; Crafts; Community collective logics; Ethnic identity; Migration

This work presents various narratives of a referent and leader qom of a community in La Plata, which deals with his migratory experience, the artisanal production in the city and the communitarian collective logics that support them. Methodologically we use what is denominated "producción de conocimiento conjunto" (production of joint knowledge), defined as a dialogue with the field - in which we understand the qom referents as interlocutors- and a dialogue with the academy - in which those conceptualizations that contribute to interpret the situation under study and overcome the classic researcher / researcher relationship are rescued-. The co-authorship of this work with the Community qom leader and artisan continues other experiences of "producción de conocimiento conjunto" throw the problematization of the theoretical notions of ethnic identity / ethnicity / social class / experience / collective communitarian logics, which allow to go deeper into the knowledge of the artisanal practice of qom people.
\end{abstract}

\section{Artesanía qom: ¿estratégia de subsistência ou laço de união e expressão do coletivo comunitário?}

\section{Resumo}

Palavras-chave

qom, artesanato, lógicas coletiva comunitarias, identidade étnica, migração
Este trabalho presenta várias narrativas de um referente e líder duma comunidade qom de La Plata, que explica sua experiência de migração, dela produção artesanal na cidade y das lógicas coletiva comunitárias que as apóiam. Metodologicamente nós usamos o que foi chamado como produção conjunta de conhecimento; definido como um diálogo com o campo - no qual entendemos os referentes qom como interlocutores- e um diálogo com a academia - no qual se resgatam aquelas conceituações que contribuem para interpretar a situação em estudo e superar a clássica relação pesquisador / pesquisador-. O co-autor deste trabalho com o líder e artesão qom da comunidade é enquadrado e é a continuidade de outras experiências de produção conjunta de conhecimento guiado pela problematização das noções teóricas de identidade étnica/etnia/classe/lógicas coletiva comunitárias, que permitem aprofundar no conhecimento da prática artesanal do povo qom.

\section{Introducción}

Este trabajo se apoya en los avances de la línea de investigación "Identidad, etnicidad, interculturalidad. Indígenas en ciudad". La misma surgió en la década del ochenta para identificar y analizar las presencias indígenas en el conurbano bonaerense, y partió de entender a la sociedad estratificada en clases sociales, para luego reflexionar y profundizar acerca de la relación entre la identidad étnica y la clase social. Así como historiza Tamagno (2001), estas reflexiones tienen su origen en las discusiones que se llevaron a cabo en las 
décadas del sesenta y setenta por intelectuales de América Latina, quienes concebían -a partir de las conceptualizaciones de Marx en relación con la clase social- a la sociedad como producto de las relaciones de mercado impuestas durante la colonización. De esta forma se ponía en discusión si los indígenas debían ser pensados como campesinos o como grupos étnicos o proletarios vendedores de su fuerza de trabajo. A partir de estas discusiones y del trabajo con nucleamientos ${ }^{1}$ qom asentados en el conurbano bonaerense, la autora reconoce que la identidad étnica y la identidad de clase no deben interpretarse como contradictorias, sino que, en su dialéctica, constituyen respuestas a los modos de imposición del blanco. Comprender a los indígenas como sujetos históricos y políticos implica reconocer que sus presencias actuales y sus modos de habitar el espacio social son transformaciones propias del proceso migratorio, pero que de ninguna manera implican pérdida de identidad (Tamagno, 2001).

En el contexto urbano, la producción y venta de artesanías qom es parte de las estrategias económicas de las familias indígenas, así como motivo de reivindicaciones identitarias en luchas sociales, culturales y políticas (Cardini, 2015; Ponzinibbio, 2016). Asimismo, este arte alude a un contexto rural, atravesado por una historia de conflicto producto de la desigualdad y subordinación, y constituye "vehículos de múltiples significados sociales, históricos y de pertenencia grupal, a través de los cuales rastreamos procesos de transformación y redefinición en el ámbito urbano" (Cardini, 2015, p. 465). Así, estas producciones presentan características que permiten comprender la vida de los indígenas que, mediante procesos de selección de elementos del pasado, continúan su vida en el presente con transformaciones, que se vinculan con las dinámicas socioeconómicas de la producción y comercialización de los objetos que elaboran.

A partir de los avances del conocimiento de la antropología económica-acerca de las transformaciones en los modos de vida de los pueblos indígenas luego de la imposición e inserción de estos en el sistema capitalista y de sus respuestas-, y de los avances y reflexiones de nuestra línea de investigación -acerca de las presencias indígenas en la ciudad y la relación entre etnicidad y clase-, pretendemos realizar un aporte al conocimiento de las dinámicas socioeconómicas del pueblo qom en contextos urbanos. El objetivo del presente trabajo es reflexionar acerca de la práctica artesanal de este pueblo en términos de la producción, la circulación y la venta de sus artesanías, a partir de una serie de entrevistas que las dos primeras autoras de este artículo realizamos al tercer autor en tanto artesano ${ }^{2}$ y referente de una comunidad ${ }^{3}$ qom y situada en la ciudad de La Plata. Seleccionamos a la producción artesanal, entre las diversas prácticas económicas de subsistencia del líder, ya que esta forma parte de la economía doméstica y constituye una respuesta a las condiciones sociales de existencia, y es al mismo tiempo desarrollada a partir de una concepción y una racionalidad socioeconómica que podemos considerar como alterna y particular de un pueblo indígena.

\section{Consideraciones conceptuales y metodológicas}

Este trabajo es producto del análisis de una serie de entrevistas realizadas al actual cacique de una de las comunidades qom de La Plata, orientadas a recuperar la experiencia de vida del referente qom en relación con la producción, la circulación y la venta de artesanías en la ciudad. Para realizar este análisis entendemos a la experiencia como la trayectoria de vida individual, la cual se
1. El término "nucleamiento" fue acuñado por Tamagno (2001) para evitar describir la situación de los conjuntos de familias qom migrantes urbanos en términos de "comunidades", concepto que no resultaba operativo para dar cuenta de la dinámica de sus formas organizativas.
2. El artesano y referente de la comunidad produce "artesanías de barro". Para ello, compra en casas de artística de la ciudad la materia prima o arcilla con la que reemplaza al barro obtenido de las lagunas de Campo Winter y Resistencia con que aprendió a modelar de chico. Las figuras que hace son lechucitas (chiyet), palomitas (qoto $)$, platitos para colgar (nqiaxaqi), mulitas (tapinec), ceniceros, máscaras (qom lashec) y manitos de la abundancia (n`uaq `achic). Según lo relata el propio artesano, se suele seleccionar qué figuras hacer acorde con lo que se venda más en las ferias o según pedidos que encarguen los compradores de las piezas.

3. Más allá de lo antes señalado en torno al concepto de nucleamiento, utilizamos en algunos pasajes el término comunidad para hacer referencia a comunidades formalmente reconocidas, así como en respuesta a las clasificaciones propias del artesano. 
construye en relación con un colectivo y con determinados condicionamientos socioeconómicos. Estos son parte de la compleja dialéctica entre la base y la superestructura, en la cual la base no se conforma de manera uniforme y estática, sino como relaciones sociales cargadas de contradicciones en permanente tensión, con una dinámica particular. Asimismo, las condiciones sociales de existencia les imponen ciertas limitaciones a los sujetos, que son ajenas a la voluntad de estos y que, aunque no puedan controlar, interpretan y guían sus acciones y comportamientos (Williams, 1977). Entendemos también la experiencia de vida del líder qom, atravesada por la identidad étnica, en términos de Bartolomé (2006), como una identidad social, la cual no excluye otras identificaciones, pero que debe ser comprendida en todas sus dimensiones y se manifiesta como etnicidad, es decir, como identidad en acción, y, por lo tanto, política. La identidad étnica está moldeada por los contextos interactivos, y guía buena parte de las conductas de los miembros que se reconocen pertenecientes a esta.

La situación laboral de los qom que residen en la ciudad, en este caso La Plata, es de desempleo o empleos temporales mal pagos, changas y planes sociales del Estado, lo que reproduce situaciones de pobreza y precariedad social. Las unidades familiares son grupos domésticos; unidades de producción, residencia y consumo, de carácter reproductivo, en las que además se transmiten normas, valores y conocimientos (Balazote y Radovich, 1992). Gordillo (1994) describe a las familias pertenecientes a nucleamientos qom como sectores domésticos que son parte de la producción periférica del capitalismo y que a su vez mantienen una especificidad no capitalista heredada de modos de vida precedentes. Estas economías domésticas garantizan su reproducción social a través del mercado, y se encuentran insertas y subordinadas al sistema dominante. El autor alude a la especificidad no capitalista como el valor de compartir, esto es, un "valor sancionado socialmente" (Gordillo, 1994, p. 56), de manera que no puede explicarse como un acto solo de conveniencia esperando recibir siempre algo en otra ocasión. Así la reciprocidad generalizada optimiza la reproducción social del grupo, pero trasciende la mera utilidad práctica. Según Gordillo (1994), la reciprocidad generalizada entre los qom no implica ausencia de conflictos, producto de tensiones entre intereses comunales y los intereses individuales o del grupo doméstico, sin embargo, posee mecanismos coercitivos, que se resignifican en los nuevos contextos, con nuevos contenidos y significados. Liliana Tamagno (2003), quien realizó su investigación con nucleamientos qom asentados en La Plata, analiza la existencia de

modos de comportamiento y ciertas normas o reglas, fundadas en la tradición y que siguen ordenando la existencia de los tobas; tanto de los que migraron hace más de 30 años como de los que han migrado jóvenes y más recientemente. Tradición cuya valoración no se explica en posturas conservadoras -como con frecuencia se interpretara- sino que implica retomar prácticas y representaciones que se han probado como efectivas en las nuevas condiciones de existencia; condiciones cuya hostilidad consiguen con frecuencia mitigar apelando a lo comunitario. (Tamagno, 2003, p. 169)

Reflexionamos sobre la producción, la distribución y el consumo de artesanías ya que coincidimos con el planteo de Cardini (2015), quien afirma que la artesanía es un vehículo de importantes significaciones, que remite a la historia del grupo y a la visibilidad etnopolítica. Las que realizan los pueblos indígenas constituyen un fenómeno económico y simbólico, cuyo análisis entonces requiere considerar de modo integrado ambas dimensiones (Benedetti y Carenzo, 2006; Ponzinnibbio, 2016). 
La producción-distribución-venta de artesanías qom es analizada entonces en este trabajo como parte de una estrategia económica en la ciudad y como vehículo de múltiples significados que aluden a elementos de un pasado, pero en continuidad con el presente. Las artesanías resignifican en la ciudad sus principales contenidos sociales y económicos en armonía con los posibles procesos de comercialización. Retomamos la noción de reciprocidad entendida como un valor social indígena que se reproduce en nucleamientos qom en la ciudad, como elemento que remite a su historia pero resignificado con nuevos contenidos en los contextos urbanos (Gordillo, 1994) y mediante normas sociales que regulan la existencia de los qom y la vida en comunidad (Tamagno, 2001, 2013). Entendemos, a partir de estos planteos, que la concepción acerca de la producción y venta de artesanías indígenas qom en la ciudad debe superar aquellas nociones que remiten a aspectos puramente culturales del pueblo indígena y separados del mercado, o aquellas que conciben la producción y venta artesanal como algo regulado totalmente por las leyes del mercado y a los artesanos como sujetos económicos que persiguen sus propios intereses. De esta forma retomamos a Trinchero, Balazote y Valverde (2007), quienes afirman que el análisis de la cuestión indígena desde la antropología económica enfrenta tres desafíos: superar y contraponerse a las concepciones de la etnografía fenomenológica que concibe un pensamiento mítico indígena que se encuentra deshistorizado; comprender a los pueblos indígenas en un contexto donde se relacionan y convergen procesos de movilización social; comprender a los indígenas como sujetos sociales que buscan dar respuesta a las nuevas condiciones de explotación y acumulación capitalista.

Cuando comenzamos con las entrevistas -mucho antes de pensar en la idea de escribir el presente artículo-, surgió la histórica tensión que caracterizó los comienzos de la disciplina antropológica, cuando la práctica profesional consistía en el estudio de las sociedades indígenas, y los indígenas eran considerados -en el mejor de los casos- como informantes a los que se les podía extraer información y, en el peor y más generalizado de los casos, como objetos de estudio. Este fue el primer punto que discutimos con el líder y artesano.

-El qom dentro de la ciudad quiere dejar de ser objeto de estudio.

- ¿Vos sentís que con nosotras sos un objeto de estudio?

-En cierta manera no, porque al entender y hablar con gente capacitada a uno se le abre cierto... cierta lógica en la vida de por qué y para qué yo pretendo entablar una conversación, no de estudio, sino de plasmar el punto de vista autóctono. Yo dije este cuestionamiento porque siempre nos usan como objeto de estudio y pareciera que vivimos en una vitrina grande y a raíz de eso muchos nos discriminan, quizá por el solo hecho de pertenecer a una etnia nativa. Yo digo etnia nativa porque siempre fuimos de estas tierras. No vinimos de otros lados. Que quede plasmado algo bueno, algo que sea interesante. (Hugo Cardozo, entrevista, noviembre de 2018)

Cabe destacar que, desde un primer momento, lejos de ser el entrevistado nuestro informante y de ser nosotras en nuestro carácter de antropólogas portavoces de la comunidad, el referente y artesano qom fue nuestro "interlocutor". Intentamos así, retomando a Bartolomé (2003), construir un tipo diferente de relación social basada en un interés común por el conocimiento, en una comunicación bidireccional, en el reconocimiento del valor del diálogo, asumiendo que con frecuencia como investigadoras resultemos interrogadas. En suma, intentamos construir una relación igualitaria "que sólo resulta factible de ser construida a partir de la amistad y la confianza" (Bartolomé, 2003, p. 210). En relación con esto, el mismo autor plantea que actualmente muchos indígenas se niegan a ser representados por la academia, ya que no quieren 
ser objeto de estudio y tampoco se ven reflejados en los escritos etnográficos. Por lo tanto, muchos de los que tienen la posibilidad de acercarse a las producciones académicas que hablan sobre ellos se animan a criticarlas y a recordar que son los protagonistas de dichas producciones, por lo que es legítimo su derecho a participar activamente como autores. Sin embargo, Bartolomé (2003) rescata el valor del trabajo etnográfico, y considera que es posible una labor con profesionales antropólogos que, lejos de cosificar a sus protagonistas, den cuenta de la alteridad.

Al vislumbrar la posibilidad de escribir este artículo, coincidimos los tres en que la construcción de este consistiría en una producción conjunta de conocimiento; cargada de dificultades y limitaciones, producto del lenguaje académico y la desigualdad entre el investigador y el interlocutor (Tamagno, Gómez y Maidana, 2011) que permean a la antropología. Sin embargo, coincidimos con las autoras citadas -una de las cuales es una referente indígena- en que esta producción conjunta es posible mediante el diálogo en simetría, el compromiso y la emoción. Tamagno (2013) reconoce a los indígenas como productores de saberes sobre la sociedad de la que forman parte y sobre el campo académico:

Entendemos que el saber acumulado por los pueblos indígenas debe necesariamente ser pensado como un saber imprescindible a la hora de reconocer cómo se produce el conocimiento antropológico, pues no sólo saben sobre sí mismos sino también sobre "nosotros". (el entrecomillado es original) (Tamagno 2013, pp. 6)

En este trabajo indagamos en la trayectoria del referente qom vinculada a su desarrollo como artesano indígena, tratando de comprender qué lógicas se desenvuelven en torno a la producción, distribución y venta de artesanías en la ciudad. Para ello tuvimos que empezar desde el comienzo, es decir, desde su nacimiento en la provincia del Chaco y la historia de toda su trayectoria de desplazamientos hasta llegar a la ciudad de La Plata, donde reside actualmente. Este recorrido fue interesante para pensar las trayectorias y los desplazamientos que muchos indígenas qom en Argentina deben realizar debido a determinadas condiciones socioeconómicas. Mediante su relato comprendimos que el aprendizaje y la producción de artesanías comienzan en la temprana infancia y su práctica continúa a lo largo de toda la vida, ya sea en "el monte" o en la ciudad.

Realizamos numerosas entrevistas abiertas con el referente entre 2018-2019 que fueron grabadas. Estas fueron llevadas a cabo en una de las salas de nuestro lugar de trabajo y en el patio de la casa del artesano, lo que nos permitió notar que los distintos contextos en que se realizaban daban lugar a indagar sobre cuestiones diferentes al generarse un "clima" distinto, según se tratara del laboratorio o del hogar del entrevistado. Fue así que una vez en nuestro lugar de trabajo, al llegar el líder qom, vio una "mano de la abundancia" (en lengua $n$ `uaq 'achic) -artesanía característica del pueblo qom-sobre una repisa y nos dijo: "Esa la hizo mi papá". Dicha frase actuó como disparador en ese encuentro para comenzar a hablar de lleno de las artesanías y de su trayectoria como artesano, ya que como nos dijera más adelante y en repetidas ocasiones, "los pensamientos me vienen con la pieza adelante. No puedo hablar si no tengo nada enfrente".

La desgrabación, lectura y análisis de las entrevistas junto al artesano y autor de este trabajo constituyeron un momento de reflexión conjunta. El proceso reflexivo fue entendido, en términos de Bourdieu, Chamboredon y Passeron (2004), como vigilancia epistemológica, tratando de controlar aquellos factores 
contextuales históricos y sociales que intervinieron en la investigación. Esta reflexividad es constitutiva de todas las prácticas que se lleven a cabo a lo largo de la investigación y no sólo como etapa final (Hidalgo, 2006). En este sentido, dicha reflexividad no fue tomada en cuenta como algo realizado únicamente por las investigadoras, sino como un asunto del cual participamos los tres autores.

Durante la producción de este artículo retomamos extractos de la narrativa del líder qom, algunos de ellos citados en el cuerpo del trabajo, referidos a sus desplazamientos y su trayectoria como artesano, y los analizamos desde concepciones teóricas referidas a la experiencia, a lógicas colectivo-comunitarias, a las migraciones, a la relación entre etnicidad y clase, entre otras. Queremos asimismo destacar que este trabajo es también producto de diversos encuentros, algunos de ellos en ferias artesanales, que no fueron grabados ni estuvieron guiados por entrevistas pero que resultaron significativos en la construcción de una relación de trabajo, amistad y confianza.

\section{La construcción de un vínculo}

Nuestro camino común se inició cuando, a principios de 2018, ${ }^{4}$ el Consejo Provincial de Asuntos Indígenas (CPAI) ${ }^{5}$ difundió la realización del "Taller de artesanías indígenas del pueblo qom" que se dictaría en la Iglesia Evangélica del Barrio Malvinas y estaría a cargo de un artesano de una de las comunidades qom de La Plata. Allí nos conocimos las dos primeras coautoras, ambas integrantes del Laboratorio de Investigaciones en Antropología Social (LIAS), quienes decidimos participar del taller en calidad de alumnas, con el tercer coautor, referente de esa comunidad, quien participó del taller en calidad de docente artesano. ${ }^{6}$

La llegada de las familias qom a La Plata se remonta al año 1991 cuando, a través del Programa PROTIERRA y del Programa Autogestión Constructiva, consiguieron lotes para iniciar la autoconstrucción de sus viviendas (Tamagno, 2001). En la actualidad existen cinco comunidades formalmente reconocidas en la ciudad de La Plata. El artesano pertenece a una de ellas, cuya personería jurídica se encuentra desde hace varios años en proceso de inscripción. En encuentros posteriores al taller surgió la idea de escribir sobre su historia de vida y fue allí cuando el líder y artesano con quien compartimos la autoría del trabajo nos indicó que deberíamos presentarnos primero en la comunidad y luego solicitarles un permiso para escribir sus experiencias de vida, y así lo hicimos. Esta situación entendemos que apela a la lógica colectivo-comunitaria, ya que, al no concebir su historia como una historia individual o como algo que le pertenece solo a él, el artesano reconoce mediante este pedido de permiso que lo que nos va a relatar es y representa-además de su experiencia personal de vida- parte de la historia de la comunidad y del pueblo en su conjunto.

La experiencia del referente y artesano qom refleja trayectorias a las que muchos indígenas de nuestro país se ven obligados a transitar a lo largo de su vida, producto de la desigualdad de clase del sistema capitalista y de la historia de despojo territorial y colonización a la que fueron y siguen siendo sometidos.
4. Cabe agregar que quienes han desarrollado la línea de investigación citada conocen al líder y artesano qom desde hace más de veinte años $y$, aunque por distintas circunstancias que no hacen al desarrollo de este trabajo no habían trabajado puntualmente con él, han tenido en cuenta a los diferentes nucleamientos qom de La Plata en sus producciones de investigación y de extensión universitaria (ver Tamagno, 2001) al tratar los procesos migratorios.

5. El Consejo Provincial de Asuntos Indígenas (CPAI) es un órgano de codecisión perteneciente a la Secretaría de Derechos Humanos de la Provincia de Buenos Aires.

6. Cabe aclarar que no existen relevamientos oficiales acerca de la cantidad de artesanos y artesanas qom que hay en La Plata, pero en la comunidad a la que pertenece el coautor de este artículo, sus miembros han contabilizado una artesana y dos artesanos. Sin embargo, es de destacar que no se entienden a sí mismos como solo tres contenidos en la frontera de su comunidad, sino que se sienten pertenecientes al grupo de artesanos del pueblo qom que hay en la ciudad o por fuera de ella, con quienes se comunican frecuentemente para ir juntos a las ferias y tender lazos de ayuda reciprocitaria. 
7. El artesano se refiere con la expresión "hermanos" no solo a los hermanos biológicos, sino también a gente que pertenece al pueblo qom; expresión común entre los indígenas de distintos pueblos.

\section{La llegada a la ciudad y la venta de artesanía: reforzando lo colectivo comunitario}

Las migraciones qom hacia las ciudades durante la segunda mitad del siglo XX pueden comprenderse como producto del despojo de sus territorios de origen, y motivadas por la búsqueda de mejores condiciones de vida. Una vez en las ciudades (Resistencia, Rosario, Buenos Aires y La Plata), debieron asentarse en las periferias de ellas. Estos desplazamientos generaron, según lo señala Maidana (2013), redes de relaciones parentales, mediante las cuales se mantienen los vínculos con aquellos que quedaron en los territorios de origen. Siguiendo a la misma autora, dichas redes también se utilizan como capital social para aquellos indígenas que quieran migrar a la ciudad. En relación con los factores estructurales que condicionaron los desplazamientos qom, se referencia la inserción de Argentina al modelo agroexportador, su conformación como Estado nación, la incipiente industrialización y como producto las políticas sociales, cargadas de violencia contra el indio que regularon y regulan la vivienda y el acceso a recursos (Maidana, 2013).

El actual cacique qom de una de las comunidades de La Plata relata que se ha desplazado de su lugar de nacimiento desde su temprana infancia y luego a lo largo de toda su juventud. Sin embargo, no está de acuerdo en ser llamado migrante, ya que, según él, migrantes son los criollos o blancos, quienes descienden de población no originaria venida de Europa. En sus propias palabras: “¡Cómo voy a ser migrante en mi propia tierra!”. Asimismo, nos cuenta que ha mantenido los lazos con los parientes que aún viven en la provincia de Chaco y que incluso algunos "hermanos" 7 se han desplazado al barrio donde reside actualmente. Durante la trayectoria del artesano en la provincia de Buenos Aires, la artesanía es y ha sido producida ante la necesidad de vender para subsistir en la ciudad.

\footnotetext{
-¿Aprendiste acá?

-No, en Chaco, porque no sabía ni albañilería ni electricidad, no sabía nada del trabajo que había. Lo único que sabía hacer era la artesanía, entonces qué mejor cosa, porque vivíamos en el campo y cuando volvíamos a la ciudad lo único que había en la ciudad era o salir a cortar pasto o hacer artesanía. (Hugo Cardozo, entrevista, noviembre de 2018)
}

Las prácticas artesanales indígenas en la ciudad se insertan en un contexto laboral caracterizado por trabajos precarios, planes sociales y desocupación. La venta de artesanías es un complemento económico para garantizar la reproducción social del grupo doméstico. Él relata que el primer trabajo que consiguió al llegar a Buenos Aires fue en una fábrica de cal; allí obtuvo un sueldo y un lugar para vivir. Asimismo, en su narración expresa que pudo reencontrarse con gente de su pueblo a través de la artesanía. Esto se volvió patente cuando, en ocasión de pasear por el barrio de Recoleta, el artesano detectó una artesanía en la vidriera de un local. No solo reconoció que esta pertenecía a su pueblo, sino también quién la produjo, en este caso, un familiar suyo. Decidió entonces esperar al artesano para reencontrarse con él, y fue así que se enteró que sus hermanos qom vivían en Quilmes (partido del conurbano bonaerense) todos juntos, por lo que no dudó en renunciar al trabajo que tenía en ese momento para irse a vivir con ellos.

-Después, paseando ahí por Recoleta, y veía las artesanías en las vidrieras, y entro y le digo a la señora, ¿viene alguien a vender esto? Sí, sí, un señor que viene de tal parte los viernes... ah bueno por favor dígale que me espere, dígale que soy 
un pariente de él, que quiero ver y nada más. Y así pasó. Iba y lo esperaba. Era un primo mío, yo sabía por la manera en que trabajaba, viste. Por eso le decía yo, y si vivían todos en Quilmes, y empezó la joda, chupi chupi. (Hugo Cardozo, entrevista, noviembre de 2018).

- ¿Pero dejaste la fábrica?

-Sí, deje y ahí estábamos todo el día viva la pepa (Hugo Cardozo, entrevista, marzo de 2018)

Ante nuestra pregunta sobre si la artesanía representa un símbolo, el líder artesano responde que "La artesanía es el mejor vocero de las comunidades, porque es un lazo". La búsqueda de la vida en conjunto teniendo que renunciar a un trabajo estable -como surge en el relato del artesano-, y siendo la artesanía el elemento que lo unió con la gente de su pueblo en el nuevo contexto migratorio, se vincula a lo que Gordillo (1994) señala como el valor social de la reciprocidad, cuya concepción no debe caer en un culturalismo romántico, sino que dicho valor se funda en las relaciones sociales de producción comunitarias. También entendemos este accionar del referente qom en función de los planteamientos de Tamagno (2013), para quien la lógica de funcionamiento comunitaria de nucleamientos qom -aunque no siempre reconocida o explicitada- ha guiado y guía actualmente los comportamientos y las dinámicas sociales de la gente que los compone en la ciudad. De esta manera, dicha lógica se opone a lógicas individualistas propias del modo de producción capitalista, sin dejar de existir mecanismos de coerción social y control para mitigar las tensiones sociales, de quienes se niegan a compartir o se ven influenciados por lógicas propias de la sociedad hegemónica de la que son parte (Gordillo, 1994).

El líder artesano también entiende a la artesanía como un transmisor de la propia cultura y del saber que le dejaron los ancianos:

-Y parte de una realidad actual, pero remontando también un poco a la historia. La historia de mis ancestros. Mis raíces. Porque yo sé bien de dónde vengo. Yo conocí a la mayoría de mis ancianos. Todo por transmisión oral... después la transmisión también es espiritual si lo dejan al que recibe. (Hugo Cardozo, entrevista, marzo de 2019)

Cardini (2015) afirma que la artesanía en la ciudad apela a la memoria, la identidad, y retoma nuevos significados producto de las migraciones y los cambios de vida. Siguiendo el relato del referente qom, las artesanías son transmisoras de familia y origen, y expresan el linaje al que pertenece cada uno; y en la ciudad, los qom son capaces de identificar todas estas cuestiones a través de las piezas, observando las formas y la pintura. Cardini (2017) afirma que, en los relatos de los qom, estas producciones aparecen haciendo referencia a momentos importantes de las biografías de cada persona; en el caso del cacique, están presentes para unirlo con la gente de su pueblo durante su desplazamiento.

Durante las entrevistas, el artesano expresa que siempre buscó vivir en comunidad, más allá de las tensiones y diferencias políticas e ideológicas que él vivenció durante la autoconstrucción de las viviendas de una asociación civil qom $^{8}$ de la que formó parte. Como muchos otros, sigue eligiendo vivir de forma conjunta en la ciudad con la gente de su pueblo y gente del barrio que no es qom, con quienes comparte la vida cotidiana. Para entender este último punto, retomamos a Maidana (2013), quien afirma que las migraciones y desplazamientos producto de la coyuntura estructural que impuso e impone el sistema de producción capitalista pueden ser entendidas en relación con los 
entramados de etnicidad y clase que responden redimensionalizando el territorio de las ciudades. Es decir, los indígenas se apropian de los espacios, los resignifican y modelan de acuerdo con sus propias lógicas culturales.

- La venta es individual, y claro, uno necesita, es como un trabajo, si no trabajas no comes. Uno necesita salir a vender algunas dos o tres cosas para salir a vender, para traer algo a la casa o si no, de última, lo cambiamos por mercadería, todo depende. O sea, a veces en estos casos de crisis, vamos y llevamos, y cierta cantidad cambio por ropa, cierta cantidad la vendo, y la gente ve y cambia como un trueque. No es que yo tengo un cartelito, esta parte cambio por ropa esta parte por mercadería, y la gente va.

- ¿Y ellos que hacen con eso? ¿Se lo quedan o revenden?

-No sé qué harán... todos están contentos, uno es feliz, eso es lo importante.

$-¿ Y$ a vos quien te enseñó a hacer artesanías?

-La necesidad. (Hugo Cardozo, entrevista, marzo del 2019)

Entender a la artesanía no solo como una mera respuesta a la necesidad -tal como reiteradas veces lo menciona el artesano- fue producto de largas discusiones que los tres mantuvimos. Las experiencias de vida del cacique en relación con la artesanía, atravesadas por su situación de pobreza, no dejan de apelar a la identidad, a la memoria, y durante la enseñanza y la venta, a valores colectivos comunitarios, compartiendo saberes y espacios de venta, buscando obtener un ingreso económico, pero sin necesidad de reproducir lógicas individualistas y competitivas.

Durante algunas ferias de artesanías de las que participamos, en La Plata y CABA, observamos que algunos artesanos no hacen sus propias artesanías. Esto no implica que no sepan realizarlas, sino que -como nos explicara el artesano durante las entrevistas- ellos les compran artesanías a otros artesanos, ya sean de comunidades de Chaco o de La Plata "para darles una mano", es decir, para ayudar al otro que necesita vender para garantizar su subsistencia, a pesar de que quien le compra también necesita. Estos comportamientos siguen reforzando la idea de que entender la producción de artesanías qom como respuesta a las situaciones de pobreza, en función de una mera estrategia de subsistencia, implica reducir la complejidad del fenómeno. La reproducción de los lazos colectivo-comunitarios producto de las enseñanzas y la vida en comunidad no es algo menor en la etapa de producción, circulación y venta, ya que aparece la intención de ayudar al otro como obligación moral, en todo momento durante sus discursos y prácticas. En palabras del artesano:

Transmisión de mi propia cultura es el saber de lo que nos dejaron los ancianos, por ejemplo, digo yo siendo nativo y aborigen de esta tierra, sé y entiendo que hay otro hermano aborigen que está haciendo lo mismo... por el tema ese del saber de la artesanía, es el mejor trasmisor de familia, de pueblo, de origen, eso es la artesanía. (Hugo Cardozo, entrevista, abril de 2019)

Los discursos del artesano y referente qom reflejan representaciones de la artesanía que significan algo más que solo una respuesta a la necesidad de subsistencia. Así, como vehículo de múltiples significados y recurso que apela a la memoria y a la identidad (Benedetti, 2012; Cardini, 2015), las lógicas que regulan su producción y venta también se encuentran impregnadas por una racionalidad socioeconómica alterna y que se diferencia de la mercantil. Dicha racionalidad responde a lo que definimos anteriormente como reciprocidad (Gordillo, 1994; Tamagno, 2001). Esta cuestión también se refleja en el discurso 
de Hugo cuando nos habla acerca de la enseñanza que imparte sobre las artesanías a niñas, niños y jóvenes de la comunidad y del barrio.

- ¿Y con qué interés les enseñas a hacer las artesanías?

-Muy sencillo. Para que se acuerden de mí algún día, yo no voy a ser eterno, para que entiendan y que amen la vida, y que no sean egoístas. Vos te das cuenta ver la sonrisa de un niño, que te abrace, muy sencillo, no podés ver una criatura llorando, te abraza y te besa, estás allá arriba. (Hugo Cardozo, entrevista, abril del 2019)

Como expresa el líder de la comunidad, que aprendan a hacer artesanías acerca a los jóvenes "a amar la vida, a no ser egoístas y alejarse de las drogas". Así intenta trasmitir valores de su pueblo y lógicas que él aprendió viviendo de forma colectiva, ya sea en "el monte" o en la ciudad. Cardini (2017) entiende que el aprendizaje y la transmisión sobre las artesanías corresponden a etapas del mismo proceso, además enseñar, no solo consiste en mostrar los pasos técnicos para hacer las piezas, en palabras de la autora, "se inscribe en y desde la historia de los grupos, en una forma de "ver" y "ser" en el mundo" (p. 115). En este mismo sentido, para Ponzinnibio (2016), los artesanos son verdaderos guardianes de la memoria y se desempeñan por esa razón como líderes.

Los chicos estos, vienen y ahora por ejemplo tengo ahí para trabajar, y dicen ¿cuándo vamos a trabajar?, y dicen ahí sí o si la mitad ocupo para trabajar con los chicos, la otra mitad lo hago yo porque es para vender. Yo para que se entretengan los chicos todo eso, los vecinos, la mayoría. ¿Sabés cuantos chicos hay acá? 72 hay. (Hugo Cardozo, entrevista, abril del 2019)

Entendemos que la enseñanza que imparte el artesano a los niños y jóvenes del barrio -con el objetivo de que aprendan algo bueno y no se droguentiene que ver con querer transmitir una forma de ver el mundo y una lógica colectivo-comunitaria propia del pueblo qom. Dicha lógica refiere a dar algo de lo que uno tiene o sabe, esperando que sea recibido y devuelto de forma recíproca; en este caso, se espera una devolución en forma de afecto de parte de los niños. En palabras del líder de la comunidad:

Ya desde el 84 que andamos en la Plata. Pero bueno, gracias a estos vaivén de la vida, nos organizamos, nos enseñaron gente buena la manera de organizarnos, y ahora seguimos luchando, esperanzados en que algún día se haya, digo que fuéramos a ver el fruto de cada uno. Justamente seguir peleando por la comunidad, no solamente porque seamos diferentes porque tengamos color diferente, lengua diferente, ya que ya estamos insertados en la sociedad, tratamos de trasmitir siempre, no solamente un saber de la comunidad, sino también es el estar mancomunados, porque nosotros aprendimos oficios en las grandes ciudades. Entonces uno anda por la ciudad como si fuera nada, pero siempre sabe que pertenece a un pueblo originario. (Hugo Cardozo, entrevista, abril de 2019)

La artesanía y el reconocerse como perteneciente a un pueblo indígena, tal como se ve en su relato, dan cuenta de la etnicidad, como producto de complejos procesos de aceptación/rechazo de los modelos impuestos, como trayectoria histórica y reconocida en un origen común. La producción y venta de artesanía en la ciudad como respuesta a las condiciones sociales de existencia, como complemento económico para la economía doméstica, es producto de la inserción del pueblo qom en el modo de producción capitalista, lo cual dio lugar a diversas transformaciones, pero que de ninguna manera implican pérdida de identidad, siempre que haya referencia a una historia común y a una descendencia o un origen común (Tamagno, 2001). 
En ese mismo sentido, Cardini (2017) afirma que la producción artesanal funciona como emblema identitario, el cual refiere a un pasado y a un origen común, que se remontan a la historia anterior a la conquista. Así, la artesanía se resignifica en un contexto de resistencia y de reproducción de los grupos subalternos, donde prima la cultura del consumo y el mercado. Estos planteos se vinculan al relato del referente qom cuando indagamos acerca de cuál fue su interés personal en aprender a hacer las artesanías cuando era chico. El líder nos contó que lo hizo por curiosidad, porque en aquel momento era un "hobby", no había necesidad de vender como en la ciudad, y él personalmente quería entender cómo se llega a hacer una vasija que luego se pone al fuego y no se rompe, cuestiones que en aquel momento le llamaron la atención. En la ciudad, la artesanía se constituye en un bien de cambio con los hermanos de Chaco que traen artesanías con materiales originarios del monte y las intercambian por comida, ropa, y/o dinero o entre los qom de la ciudad, quienes las utilizan en trueques durante las ferias en las que participan. En el monte -dice el artesano- "la práctica artesanal se sigue llevando a cabo por deporte", ya que allí no hay a quién venderle como en la ciudad, por lo tanto muchas veces se hace para regalar a familiares que vienen de visita. Durante la vida en el campo, cuenta que aprendió a hacer artesanía por la curiosidad arriba mencionada y además porque era necesario aprender de todo.

- ¿Y eso que decías, que hacen las piezas depende de lo que se vende, funciona igual en la ciudad y en el monte?

-No, en el monte, a quién le vas a vender, ya se hace más por deporte, o porque llega un familiar tuyo de la ciudad y le regalas y es nada más que para eso, por hobby ya se hace, no se hace para vender, ya en el campo tenés de todo, tenés sandía, choclo, plantaciones de banana, fruta, de todo tenés, en el campo no se sufre lo que sufrís en la ciudad. (Hugo Cardozo, entrevista, abril de 2019)

La trayectoria de la producción artesanal en la ciudad remite a la identidad, a la memoria, al origen común, pero se resignifica ante las necesidades del mercado y consumo al cual se orienta su producción, y ante las nuevas necesidades económicas de la vida en la ciudad.

En relación con lo anterior, cuando indagamos acerca de los significados de distintas piezas de cerámica, respecto de una de ellas -n 'uaq `achic-, el artesano nos explicó:

Según mi abuelo, me decía que era mostrar sinceridad, humildad, porque yo no te puedo conocer si no me mostrás tu mano, si no me decís con qué venís pensando. Cuando uno da la mano sabe que hay en tu corazón, la simpleza, sinceridad, hay muchas maneras de conocer la persona, eso si tenés calle, conoces, andas y no te pueden joder a tiempo, o si podés, si te haces el tonto, como si fuera que no pasa nada, el que lleva la incógnita es el otro, porque no sabe si vino de una manera distinta pensando distinto o, eso es la manera de conocer. (Hugo Cardozo, entrevista, abril de 2019)

La forma de pensar y sentir del artesano qom está atravesada por la historia de su pueblo, que manifiesta y encarna actualmente mediante sus prácticas sociales, en este caso en relación con la artesanía. Experiencias actuales que se vivencian desde lo afectivo, como un pensamiento que se siente y un sentimiento que se piensa, es decir "una experiencia social en proceso" (Williams, 1977, p. 155), que, a pesar de ser personal, debe ser reconocida como social y estructurada por elementos en permanente tensión (Williams, 1977). Las estructuras del sentimiento son aquellas formas de pensamiento y sentimiento que 
se vivencian en el presente. Estas se construyeron en relación con un pasado y una experiencia colectiva; sin embargo, no solo documentan la historia, sino que se expresan mediante la experiencia actual (Williams, 1977). Así, las lógicas reciprocitarias que se expresan en las prácticas y discursos del referente qom, del cacique, forman parte de la conciencia práctica y muchas veces se ponen en tensión con las lógicas individualistas propias de la sociedad hegemónica.

\section{A modo de cierre}

Si bien en la provincia de Buenos Aires, la artesanía es y ha sido producida ante la necesidad de vender para subsistir en la ciudad, esta se resignifica en la ciudad como símbolo de lazo y vocero de las comunidades del pueblo qom, apelando al linaje, a la identidad, la memoria y a moldear el territorio que ocupan actualmente, de acuerdo con lógicas culturales propias del pueblo.

La venta de artesanías se inserta en un contexto socioeconómico de pobreza, falta de empleo y precariedad social, en que el ingreso que obtienen de la venta conforma un complemento a la economía doméstica. Sin embargo, concebir esta práctica sólo como mera respuesta a la necesidad económica implica caer en un reduccionismo, que impide ver la complejidad de la práctica artesanal. Asimismo, supone otorgarle a dicha práctica una lógica mercantil, la cual no es la que se expresa durante la producción y la venta de los productos. La experiencia del artesano, si bien es personal, también es producto de una construcción colectiva, y durante su narrativa apela a la identidad, a la memoria y a valores colectivo-comunitarios. Puede considerarse que dichos valores conforman una racionalidad socioeconómica alterna, que es disidente respecto de la lógica que plantea el modelo económico capitalista, y se reproduce durante la enseñanza de la práctica artesanal, la producción, circulación y venta. Entendemos que la reciprocidad que se expresa en las prácticas y discursos en torno a los valores y a la actividad artesanal se ponen en tensión con los razonamientos individualistas propios de la sociedad hegemónica, y que sin embargo no consideramos que sean ajenos a la vida actual del pueblo qom.

Así, la práctica artesanal forma parte de una estrategia económica de sobrevivencia en la ciudad como respuesta a las condiciones de pobreza, pero al mismo tiempo está impregnada de valores socioeconómicos alternos y particulares del pueblo qom, y conforma un recurso que apela a la identidad, la memoria y los lazos colectivo-comunitarios.

\section{Financiamiento:}

"Este documento es resultado del financiamiento otorgado por el Estado Nacional, por lo tanto queda sujeto al cumplimiento de la Ley № 26.899 ”. Este artículo constituye un avance del Proyecto de Investigación "Pueblos indígenas. Presencias y demandas. Aportes desde la antropología al tratamiento de la interculturalidad. Diversidad/ desigualdad" (Código 11/N845) acreditado por la Universidad Nacional de La Plata.

\section{Agradecimientos:}

Los tres autores agradecemos especialmente a la comunidad por permitirnos plasmar en este artículo saberes, historias y memorias propias y de su pueblo. 


\section{Q Referencias bibliográficas}

» Balazote, A. y Radovich, J. C. (1992). El concepto de grupo doméstico. En H. Trinchero (Comp.), Antropología Económica II (pp. 27-43). Ciudad de Buenos Aires: Centro Editor de América Latina.

" Bartolomé, M. (2003). En defensa de la etnografía. El papel contemporáneo de la investigación intercultural. Revista de Antropología Social, 12, 199-222.

» Bartolomé, M. (2006). Los laberintos de la identidad: procesos identitarios en las poblaciones indígenas. Avá. Revista de Antropología, 9, 28-48.

» Benedetti, C (2012). Producción artesanal indígena y comercialización: entre los "buenitos" y los “barateros". Maguaré, 26 (1), 229-262.

» Benedetti, C y Carenzo, S. (2006). Producción artesanal indígena: una aproximación a la problemática en la comunidad Chané de Campo Durán (Salta, Argentina). Intersecciones en Antropología, 8, 315-326.

» Bourdieu, P., Chamboredon, J. C y Passeron, J. C. (2004). El oficio del sociólogo. Presupuestos epistemológicos. Buenos Aires: Siglo XXI.

»Cardini, L. (2015). Producción artesanal indígena entre la identidad étnica y las exigencias del mercado. En S. Pérez Ramírez (Ed.), Artesanías y saberes tradicionales, Vol II (pp. 463-498). Michoacán: Colegio de Michoacán.

»Cardini, L. (2017). El trabajo de los qom. Artesanías, cultura y construcción política en Rosario. Rosario: Prohistoria.

» Gordillo, G. (1994). La presión de los más pobres: reciprocidad, diferenciación social y conflicto entre los tobas del oeste de Mendoza. Cuadernos del Instituto de Antropología y Pensamiento Latinoamericano, 15, 53-82.

" Hidalgo, C. (2006). Reflexividades. Cuadernos de Antropología Social, 23, 45-56.

» Maidana, C. (2013), Territorios indígenas Entramados de etnicidad y clase. Quid 16. Revista del Área de Estudios Urbanos, 3, 66-81.

"Ponzinibbio, J. (2016). Las “Lechucitas” Qom, aportes para la interpretación de la artesanía indígena (tesina de grado). Facultad de Bellas Artes, Universidad Nacional de La Plata, La Plata, Argentina.

» Tamagno, L., Gómez, J. y Maidana, C. (2011). Los caminos de la investigación. Acerca de verdades y utopías. En J. de Souza y C. Maidana (comps.), Antropología de los nativos. Estrategias sociales de los sujetos en la investigación (pp. 173-182). La Plata: Editorial de la Universidad de La Plata.

» Tamagno, L. (2001). Nam qom hueta'a na doqshi Ima'. Los tobas en la casa del hombre blanco. Identidad, memoria y utopía. La Plata: Al Margen.

» Tamagno, L. (2003). Identidades, saberes, memoria histórica y prácticas comunitarias. Indígenas tobas migrantes en la ciudad de La Plata, capital de la Pcia. de Buenos Aires Argentina. CAMPOS, 3, 163-182.

» Tamagno, L., Gómez J., y Maidana C. A. (2011). Los caminos de la investigación. Acerca de verdades y utopías. Antropología de los nativos. Estrategias sociales de los sujetos en la investigación. J de Souza y C, Maidana (comp) de EDULP, 173-182.

" Tamagno, L. (2013). Lo comunitario. Expresiones identitarias, proyectos y utopías de los migrantes qom (tobas) urbanos de Argentina. Simposio "Historias de vida comu- 
nitaria, proyectos (indígenas y afro) de vida en común". Simposio llevado a cabo en el VII Congreso Internacional CEISAL (Consejo Europeo de Investigaciones Sociales sobre América Latina) Memoria, Presente y Porvenir en América Latina. Universidad Fernando Pessoa en Oporto (Portugal).

» Trinchero, H., Balazote, A., y Valverde, S. (2007). Antropología Económica y Ecológica: recorridos y desafíos disciplinares. Cuadernos De antropología Social, (26), 7-19. https:// doi.org/10.34096/cas.i26.4337

»Williams, R (1977). Marxismo y literatura. Buenos Aires: Manantial. 
